\title{
Exhibiting library collections online: Omeka in context
}

Juliet L. Hardesty

Metadata Analyst

Indiana University

Bloomington, Indiana

jlhardes@iu.edu

(C) 2014 Juliet L. Hardesty

This work is licensed under a Creative Commons Attribution 4.0 International

License. (http://creativecommons.org/licenses/by/4.0/)

\section{Introduction}

For Indiana University (IU) Libraries, and for most libraries out there, our collections comprise more than just books. We have more than just a series of things on a shelf with descriptions that can be searched. We have items that are part of a larger donated set; we have original pieces that tell a story or are part of a story in history; we have art objects; we have sound and moving pictures; we have born digital items; we represent and reflect our community. All of these items are in the library (or gallery, archive, or museum) to be preserved, viewed, and researched. Many times, however, those goals are conflicting, particularly for physical items. Digital library efforts have pursued digitizing and providing some kind of online access to as much content as possible. These efforts can result in specialized web sites focused on a particular collection using functionality so specialized to the collection or metadata as to be unusable anywhere else. In the opposite direction, online access can come in the form of web sites focused solely on a format resulting in the loss of context and significance. How can we reveal the significance and context of individual items and provide access to them in a way that makes them more collectively available? Online exhibition tools allow libraries (along with galleries, archives, and museums) the opportunity to provide access to items that are fragile, popular, or both and that have a story to be shared, regardless of the digital management process.

These were our needs at the Indiana University Libraries - to find an alternative to both specialized collection sites with functionality that cannot be generalized and repository-based service sites that offer an aggregation of items based on format (i.e., images) or type of content (i.e., archival finding aids). We satisfied this need using Omeka, an open source online exhibition software tool from the Roy Rosenzweig Center for History and New Media at George Mason University. Following is the full story of IU Libraries' use of Omeka, and includes other uses for Omeka that have developed at IU, an examination of available online exhibit tools, and what our use of Omeka means to IU Libraries' digital collections moving forward.

\section{Omeka Overview}


Omeka is an open source online exhibit tool for galleries, libraries, archives, and museums (GLAM) that offers two different versions, omeka.org' ${ }^{1}$ and omeka.net ${ }^{2}$, with some significant differences. Omeka.org is an open source software package that can be downloaded and installed on a local web server giving access to all of the code that makes Omeka work. This requires a full web site setup: operating system (such as Linux), web server (Apache), along with a MySQL database, PHP, and ImageMagick $^{3}$ (a native PHP extension that enables dynamic creation of thumbnailsized images from original images that are loaded into Omeka). While omeka.org offers the most options for curating and publishing digital objects, this route also involves needing the resources and skills to serve as system administrator, programmer, and exhibit manager - it is all in your hands.

Omeka.net is a hosted service, similar to online image gallery services like Flickr and eHive in that you can sign up for an account and upload content that lives on someone else's web server. You still have all of the exhibit capabilities that come with Omeka and can use the administrative interface to manage your content and exhibits, but you are not in charge of the database or the code that makes Omeka run. The service is free up to a certain point, beyond which different annual plans can be purchased to provide increasing amounts of storage and features. Additionally your content and exhibits can only be managed and edited via the Omeka.net administrative interface, so there are limitations on things like customizing layouts.

For the purposes of explaining how Omeka is being used in the library at Indiana University, the features discussed from this point on are in reference to Omeka.org, the standalone software package that is locally installed and managed. Part of what makes Omeka work well as an open source web site tool is that a community has grown around the core software and plug-ins have been developed to perform a variety of functions, from batch importing images and metadata to creating exhibitions and timeline visualizations of a collection. If a feature is desired but the default install of Omeka does not supply that feature, available plug-ins might contain that functionality (similar to other web services like WordPress or Firefox browser plug-ins). Additionally, if the desired functionality is not available as part of the existing suite of Omeka plug-ins, a framework exists that you can use to develop your own plug-in solution and share with the Omeka community.

Each site created in Omeka can have a different look and feel based on themed presentations, which are chosen within the administrative interface. For Omeka.org, if you know HTML/CSS you can easily modify a theme in any way you like or create your own themed presentation. Omeka.net offers a selection of themes but they can only be customized to a certain point via the administrative interface.

1 http://omeka.org

${ }^{2}$ http://www.omeka.net

3 http://www.php.net/manual/en/book.imagick.php 
Another feature that makes Omeka interesting as an exhibit tool is the capability to tag items with keywords. This feature aids in browsing and organizing content that would not otherwise be organized or easily viewable in a particular way. One of Indiana University's examples shows how Omeka tags can be used to provide enhanced user interaction.

Since the Omeka community has been growing, the number of plug-ins and themes, the support on Omeka forums, and the list of example sites are all increasing. Additionally further development by the Roy Rosenzweig Center for History and New Media has produced Omeka 2.0 and work has begun on Omeka 3.0, showing continued commitment to this software and its community.

\section{Omeka at Indiana University}

The War of 1812 in the Collections of the Lilly Library

The most prominent Omeka example at Indiana University is "The War of 1812 in the Collections of the Lilly Library." ${ }^{4}$ The Lilly Library, which houses IU's rare books and special collections, has a strong collection of artifacts from the War of 1812. With the $200^{\text {th }}$ anniversary of the war in 2012, the IU Libraries decided a physical and online exhibit of these rare pieces was appropriate. The War of 1812 affected the land that is now Indiana, Michigan, and Ohio in addition to the northeastern United States. This was also the last time the U.S. invaded Canada and was the first conflict to produce a nation-wide sense of patriotism, as evidenced by the penning of the future national anthem, "The Star-Spangled Banner," in 1814.

The Lilly Library's collection of war artifacts includes maps, correspondence, prints, books, and even sheet music, so a wide variety of materials would be on display and would need to be presentable online. At the time, IU Libraries' digital collections were being offered online via distinct services that provided access to different types of digitized content: a finding aids site for correspondence ${ }^{5}$, an images site for prints and maps ${ }^{6}$, a page-turning web application linked directly to the library catalog for digitized books ${ }^{7}$, and even a service for offering access to digitized sheet music. $^{8}$ What we did not have was a way to bring those different types of materials together online to present a cohesive collection on a single topic (like the War of 1812).

${ }^{4}$ http://collections.libraries.iub.edu/warof1812/

${ }^{5}$ Archives Online - http://dlib.indiana.edu/collections/findingaids/

${ }^{6}$ Image Collections Online - http://dlib.indiana.edu/collections/images/

${ }^{7}$ Outdoor Indiana displayed using METS Navigator http:////purl.dlib.indiana.edu/iudl/general/VAA3736

8 IN Harmony: Sheet Music from Indiana http://dlib.indiana.edu/collections/inharmony/ [or Sheet Music Consortium http://digital.library.ucla.edu/sheetmusic/]????? 
Our evaluation of online exhibit tools led us to Omeka (version 1.4.1) due to its ability to most easily combine our content without actually creating a separate site that required redoing the online display of all the items. Since our services already provided online access to the digitized material, the exhibit site only needed to offer a way to search and browse the combined items and provide topical context.

Viewing the actual items would mean going to the original service site. For example, the exhibit site needed to show all War of 1812 maps, but viewing each map would actually take the user to our image service site, Image Collections Online where the digitized version of the map was already available with full metadata and specialized tools to zoom in and out on map details. Using Omeka's CSV Import plug-in we were able to bring in thumbnail-sized images and common metadata across all materials to create the set of objects in Omeka that were indexed and searchable. ${ }^{9}$ Then instead of using item pages in Omeka for viewing individual item details, the persistent URLs that take users to detailed item views in our external services were programmed as the links for items on Omeka's search results pages. This functionality required some changes within the core programming code of Omeka, but it was made possible by a very capable group of developers in the library who were able to work on this project. We used Omeka's Exhibit Builder plug-in to create sections of content that highlighted and tied items together, giving the online site a virtual space to expand on the artifacts that were on display in the physical exhibit. ${ }^{10}$ Finally the Timeline plug-in (now deprecated in lieu of NeatlineTime from Scholars' Lab) allowed for a time-based visualization of the items in the exhibit in relation to events during the war and around the world. ${ }^{11}$

The end-user interface for Omeka sites is created using "themes," a directory of PHP code, images, and cascading style sheets (CSS) that is separate from the core functional code and plug-in code. Several themes are available for use with Omeka.org, often supplied by the community that has grown around the tool. The War of 1812 started with the default theme and was customized to create a site that captures 200-year-old artifacts from the war and allows for easy reading and image access. Additionally the structure of the HTML was changed to use HTML5 and ensure that the content met web accessibility standards (WCAG 2.0). These changes involved some work in the core functional code, touching search forms and HTML header information.

A final bit of work for the War of 1812 site was to make a mobile-optimized version for handheld devices, particularly smartphones. This site was an accompaniment to a physical exhibit so it made sense to offer a mobile version for use while walking through the Lilly Library and seeing the physical objects depicted and explained in the online exhibit. Mobile optimization was achieved using CSS media queries to detect the user's device screen size and then load an additional cascading style sheet

9 http://omeka.org/codex/Plugins/CSV_Import_2.0

${ }^{10} \mathrm{http}$ ://omeka.org/codex/Plugins/ExhibitBuilder_2.0

11 http://omeka.org/add-ons/plugins/timeline/ 
to arrange the content and functionality for the most effective use on a smaller screen (Andrew, 2010). There was no need for a separate site or URL, just an additional CSS file in the theme and an additional $<$ meta $>$ and $<$ link $>$ in the HTML header for the site (the HTML header was contained in the core PHP code but was a minor change).

\section{Student Life at IU}

A different type of site implemented in the IU Libraries using Omeka.org is Student Life at IU. This site highlights items in the University Archives related to student activities through the years. It was also the first Omeka site in the IU Libraries and published mostly by the content managers with little involvement from the technology staff in the library. Similar to the War of 1812 site, this site uses Omeka's Exhibit Builder plug-in to combine items to tell different stories (although there are multiple exhibits instead of just one). Student Life at IU is built on an earlier version of Omeka (1.3.2) and makes use of Omeka's Item pages. Each digitized item was loaded individually through the Omeka administrative interface instead of imported using the CSV Import plug-in, so all metadata and image access is maintained within the Omeka site. The theme for this site was again customized for a specific look and feel and changes were made for web accessibility and mobileoptimization.

\section{Mobile optimization within Omeka}

It is worth noting that more recent themes and updates to themes available in Omeka are using responsive design, a method of web site design meant to provide an optimal viewing experience on any web-enabled device. ${ }^{12}$ Specifically the Omeka Foundation theme and the latest version of the Thanks, Roy theme are noted as themes incorporating responsive web design. ${ }^{13}$ This means less of a need to make changes for mobile optimization. However, this also means customizations require more vigilance to make sure the basic structure and layout are not disrupted as the screen size changes.

\section{Other uses of Omeka at IU}

Beyond the two Omeka examples already described - which bring content together from various online sources and use Omeka as the content provider - Indiana University Libraries is involved in other projects using Omeka. Developers within the library are creating new plug-ins for Omeka to work with different types of digital content in new ways (video, audio, and geographic). ${ }^{14}$ Librarians are using Omeka to quickly implement new collection exhibits online and offer access to

12 http://en.wikipedia.org/wiki/Responsive_web_design

13 http://omeka.org/add-ons/themes/

14 Cowan, W. NEH Digital Video in Omeka 2.0. http://www.dlib.indiana.edu/projects/omeka2/. Retrieved November 1, 2013. 
digital collections. ${ }^{15}$ Even outside of the library Omeka is being used at Indiana University. Instructors and students are using Omeka in the classroom to learn about creating web sites and exploring digital humanities topics for better understanding and better access for research. ${ }^{16}$ For example, classes taught in the English Department have tended to start with Omeka.net for student projects and then transition to a library-supported instance of Omeka.org if the highlighted collection is part of the library. The Department of Information and Library Science's graduate course on Digital Libraries makes Omeka part of its pedagogical toolset for teaching students how to provide access to online digital collections. ${ }^{17}$

Not all attempts to use Omeka at Indiana University have resulted in success, however. In one undergraduate humanities course, certain concepts around exhibiting online digital collections in Omeka were not intuitive without some familiarity in dealing with digital collections. Organizing metadata by item and requiring plug-ins to actually create an exhibit, for example, are not well-known concepts outside the library and technology areas of the university. Some attempts at exhibiting different types of content have not always worked well with the Dublin Core metadata standard used by default in Omeka. Book collections are not necessarily a good fit with Dublin Core's limited bibliographic description capabilities, for example. And in something of a paradox, while starting off with Omeka can make creating an online exhibit easier, increasing familiarity and customization attempts in Omeka through HTML and CSS changes actually can reveal the limitations of Omeka as a web site creation tool.

\section{Literature-based Tool Assessment}

Omeka exists in a fairly vast playing field of tools and service, both open source (free to download, use, and customize) and pay (hosted services or software that require purchase), offering a range of capabilities from digital object management and collection access/exhibition to exhibition only. Libraries, archives, and museums have experimented with many of these systems over the years. Reporting on these experiences in the literature has not involved much in the way of critique but rather a description of the software or a "use case"-style story of how the software worked for a particular situation or collection.

15 Irmscher, C. Walt Whitman at the Lilly Library. http://www.indiana.edu/ liblilly/digital/exhibitions/exhibits/show/whitmanlilly. Retrieved November 1, 2013.

16 Patino, B. Documenting Empire: Frank L. Crone's photographs of colonial Philippines.

http://www.indiana.edu/ liblilly/digital/exhibitions/exhibits/show/crone.

Retrieved November 1, 2013.

17 Walsh, J. Syllabus: Z652 Digital Libraries, Fall 2013, Section 6938. http://ils.indiana.edu/faculty/jawalsh/teaching/slis/s652/2013f/. Retrieved January 3, 2014. 
The following table contains software with exhibition capabilities, however not all of these tools were discussed in the literature. The literature-based tool assessment presents a survey of scholarly and periodical reports on using open source tools designed for galleries, libraries, archives, and museums (GLAM), and then moves to software in the same category that requires payment to use or acquire. These are followed by software that has not been designed for galleries, libraries, archives, and museums, but is free and has been used and discussed in the GLAM context. This snapshot of the current landscape for providing access to online digital collections, while extensive, is more than likely not exhaustive. The nature of software design for exhibition and collection access is very dispersed and use of these tools is also spread widely. Resources and levels of experience at different institutions create situations where one tool is never going to be the answer for everyone.

\begin{tabular}{|c|c|c|c|c|c|c|c|}
\hline Software & $\begin{array}{l}\text { Open } \\
\text { Source }\end{array}$ & $\begin{array}{l}\text { Hosted } \\
\text { Service }\end{array}$ & Pay & Free & $\begin{array}{l}\text { Manages } \\
\text { Digital } \\
\text { Objects }\end{array}$ & $\begin{array}{l}\text { Designed } \\
\text { for } \\
\text { GLAM }\end{array}$ & $\begin{array}{l}\text { Discussed } \\
\text { in } \\
\text { Literature }\end{array}$ \\
\hline $\begin{array}{l}\text { Archivists' } \\
\text { Toolkit \& } \\
\text { Archon }\end{array}$ & & & & & & & \\
\hline CollectionSpace & & & & & & & \\
\hline CollectiveAccess & & & & & & & \\
\hline ContentDM & & & & & & & \\
\hline eHive & & & & & & & \\
\hline Flickr & & & & & & & \\
\hline Islandora & & & & & & & \\
\hline KE Emu & & & & & & & \\
\hline Mimsy XG & & & & & & & \\
\hline Museolog & & & & & & & \\
\hline $\begin{array}{l}\text { Museum } \\
\text { Archive } \\
\text { Software } \\
\text { Project }\end{array}$ & & & & & & & \\
\hline Omeka.org & & & & & & & \\
\hline Omeka.net & & & & & & & \\
\hline Open Exhibits & & & & & & & \\
\hline Open Museum & & & & & & & \\
\hline Pachyderm & & & & & & & \\
\hline Past Perfect & & & & & & & \\
\hline Second Life & & & & & & & \\
\hline VuDL & & & & & & & \\
\hline WordPress.org & & & & & & & \\
\hline WordPress.com & & & & & & & \\
\hline
\end{tabular}

Table 1. Online exhibit software overview and indication of intended use by galleries, libraries, archives, and museums (GLAM). 
Open Source Tools Used by Galleries, Libraries, Archives, and Museums

The following open source tools provide the closest equivalent to omeka.org, the software package that can be downloaded and installed. Some of these tools are more complex to use and some do not provide as many capabilities as omeka.org, but they are all available to freely grab and try.

In the category of full digital object management, Islandora connects Fedora Commons (Fedora), digital repository software for managing and preserving digital objects, with the front-end interface of Drupal and the searching of Solr, according to its creators at the University of Prince Edward Island's institutional repository (Moses and Stapelfeldt, 2013). Islandora offers ways to manage front end exhibits via a content management framework and customizable searching and faceting functionality. This tool is open source and offers many capabilities for experienced web developers working with digital repositories. Vassar College presented on the use of Islandora to offer access to a collection of student diaries from the early days of the institution (Di Pasquale et al., 2013). ${ }^{18}$ Built on the objects accessible from Fedora, the collection as an object and the subsequent items as objects are available directly from the same interface that allows for searching the entire digital repository. This tool is effective if a library wants to use its digital repository as the source of image content, but development time is extensive.

CollectiveAccess is an open source digital asset management system that comes in two parts: Providence is the core cataloging tool and database application (webbased in PHP/MySQL) and Pawtucket is the end user discovery and access web module (also PHP-based). Bruce High Quality Foundation University (BHQFU) is an artist collective that used CollectiveAccess to quickly create an online public access catalog (OPAC) and digital archive of the collections produced by the member artists (Weist, 2010). They received help from CollectiveAccess but were able to implement the PHP web application. The system uses Dublin Core metadata but can also work with other metadata standards. The mechanics necessary and the degree to which one can customize the end user interface are not clear (CSS knowledge is necessary but there are no further details - CollectiveAccess helped BHQFU with their end user interface implementation as well). BHQFU reported being satisfied with the product and capabilities it provided, but looking at their site now it is not clear if this catalog/digital archive is still in use. ${ }^{19}$ Other CollectiveAccess examples show heavy use of geo-referencing tools and the capability to handle audiovisual

18 http://digitallibrary.vassar.edu/collections/studentdiaries

${ }^{19}$ BHQFU web site: http://www.thebrucehighqualityfoundation.com. The library is online at

http://www.thebrucehighqualityfoundation.com/collectiveaccess/pawtucket/ but it only contains 47 items and the most recent additions appear to be from 2010 . 
materials. ${ }^{20}$ For libraries, this could be an option particularly if a digital repository is not available to manage the objects that need to be exhibited.

Archivists' Toolkit and Archon are two software efforts that have combined forces to provide archival management and standards along with end-user access and finding aid display. These tools are available now but recently the team behind this software (University of Illinois for Archon and University of California-San Diego and New York University for Archivists' Toolkit) released ArchivesSpace, the latest version meant to provide both front-end access and back-end processing. ${ }^{21}$ It is still early days for this new product (which is open source but without much documentation at the moment and with a paid membership model), but all of this software is geared towards collections using archival organization - series, boxes, folders, and items (Schwartz et al., 2007; Schaefer, 2010). Unless a library is managing its digital objects using finding aids, this is probably not the best route for exhibiting those objects.

CollectionSpace is an interesting open source tool from the museum world for managing, preserving, and providing access to digitized items. This system offers more than just discovery and access and, as reported by the Museum of the Moving Image, maintains a dedication to user-centered design that is admirable (Forbes, 2012). It is a web-based tool using Java with a relational database (PostgreSQL or MySQL) so installing and functional customization would require system administrative or developer knowledge. Once installed, however, customizations to the web interface are manageable via editing HTML and CSS files. This is another tool that would be an option for a library if its digital objects were not being managed already through a digital repository tool like Fedora.

Pachyderm is an open source tool for producing multimedia exhibits online using either Adobe Flash or HTML5. It produces a guided display with few discovery capabilities. As described in an article from the San Francisco Museum of Modern Art (MOMA) and The New Media Consortium, it uses a template system with prescribed layouts for inserting text and multimedia (Samis et al., 2007). Originally funded by the Institute of Museum and Library Services (IMLS) and involving the San Francisco MOMA along with other museums and universities, this project offers ways to exhibit collections but with varying limitations (number of layers/screens allowed, number of links out allowed, even number of words/characters allowed per screen). For a kiosk-style interface, libraries could find this software useful but online exhibits might feel limited without any way to search or freely browse a collection.

Open Exhibits is an open source tool for creating gesture-based exhibits for Adobe Flash Player using Creative Markup Language and Gesture Markup Language. Described as a software development kit (SDK) for Adobe Flash and Adobe

20 http://www.collectiveaccess.org/about/users

21 http://www.archivesspace.org 
Integrated Runtime (AIR), the project is sponsored by the National Science Foundation and geared towards museum kiosks and mobile devices. Engaging an audience with a collection through gesture interactions is interesting, but exhibit authors/editors seem to need to engage with these markup languages, and developers wanting to customize or add functionality have to be able to work in Adobe Flash products, which are not open source. Libraries might find this tool interesting for online exhibits but the Adobe requirements for back-end development could also limit the feasibility of using this tool.

Tools Used by Libraries, Archives, and Museums Requiring Payment to Use or Acquire

The following tools are commercially licensed software that has to be purchased from a company before it can be installed and used. Many times this software also requires ongoing support from the company for maintenance or enhancements, but less technology expertise is required to use these in comparison with open source tools.

Past Perfect is a system that manages digital objects and their display online, but this software is commercially licensed and managed by the company. This means there is no need to be technically knowledgeable and the company can customize your metadata and import your objects, as reported by the experience at Western Kentucky University Library and Archives (Lathrop et al., 2010). Even though libraries and archives along with many historical societies use Past Perfect for end user access, the online display of collections seems to be more of an afterthought. A report on archival management software from the Council on Library and Information Resources in 2009 explained that Past Perfect could offer a web-based catalog of a collection with the additional purchase of the Past Perfect Online module (Spiro, 2009). From the examples provided in Past Perfect's client list, the end user catalog sites look dated in design and do not offer easy ways to access images. The browse feature in Past Perfect is based on alphabet letter links for metadata fields and search is available, but image names shown in results are generally call numbers or image identifiers instead of titles or other descriptive information about the image content.

ContentDM is another complete package system for digital object management and display and access. Offered by OCLC, this software can be purchased and installed for use at an institution or hosted by OCLC for a fee. It uses the Dublin Core metadata standard and management is handled through a desktop client. The Digital Initiatives Liaison Librarian at the Dr. Martin Luther King, Jr. Library at San Jose State University cites Frank Cervone describing ContentDM as more of a database management system than a repository - it keeps track of digital files and the relationships between those files (Higgins, 2012). The latest release (ContentDM 6) includes an improved user-centered design with the possibility of greater customization without requiring programming knowledge ("OCLC launches redesigned CONTENTdm," 2011). 
Free Tools Used by Galleries, Libraries, Archives, and Museums

The following tools are mostly hosted services that, similar to omeka.net, can be used for free, at least up to a certain point. There are often limitations on the amount of space available, which is where payment options often occur to gain more space, and features are sometimes limited unless the paid version of the service is used. Depending on the size of the collection and the needs of the audience, however, the free versions of these services can be useful for online exhibition purposes.

WordPress, similar to Omeka, is blogging software that comes in two varieties: Wordpress.com is a hosted blogging site and Wordpress.org is free blogging software that can be downloaded and installed on a webserver. WordPress is a familiar tool outside of galleries, libraries, archives, and museums so it is potentially easier to pick up and use than other available tools (Bogan, 2011). Bogan refers to what some library examples have created as "catablogs." WordPress does not provide very powerful search capabilities but it can be set up to show content in different ways (ordered alphabetically and grouped in categories). The Scriblio plug-in for WordPress by Plymouth State University allows data to be structured for better searching and browsing and allows for basic exhibit creation (a WordPress page with text that can link to individual items). Scriblio uses Dublin Core for metadata and allows fields to be hidden from the end user interface. Scriblio is limited to JPG file types (no audio or video), only one image per item, and appears to have a small user community. The last example from Bogan describes using the latest version of Scriblio at her institution, Cleveland Colby Colgate Archives - CCCA at Colby-Sawyer College. That site now shows as being an Omeka site and not a WordPress site, however. ${ }^{22}$

Flickr is a hosted service for sharing images online. ${ }^{23}$ Many institutions and collections have tried using Flickr in various ways over the years, from aggregating collections for better online exposure to sharing digital collections for end user tagging and commenting (Jett et al., 2013; Stephens, 2006). What tends to be a common theme is that this service is not a place for managing a digital collection, even though space can be purchased for a relatively minor cost and it does work to provide access and a social avenue for audience engagement (Ekart, 2012). Flickr Commons, a project in partnership with the Library of Congress, is a prime example of using Flickr for online access to digitized collections and gathering usercontributed information. ${ }^{24}$ If a main goal of a library collection is to gather usercontributed information, this form of online exhibition could prove quite effective.

22 http://haystack.colby-sawyer.edu (viewing the HTML source of the page reveals Omeka RSS and Atom feeds along with Omeka plugin and theme paths)

23 http://www.flickr.com

24 http://www.flickr.com/commons 
Second Life as a software tool has become fairly abandoned by libraries at this point. Its inclusion in this review is merely for completeness and to witness the interest in 3D exhibit environments and the extent of libraries experimentation with technology. Second Life is a virtual online space where people, places, and things can interact free from physical world boundaries (such as space and time). ${ }^{25}$ This would seem an ideal space for offering exhibits of digitized collections, but Second Life as a place is very separate from the Internet as well as the physical world, so anything in Second Life cannot be discovered without first entering Second Life. Additionally, an exhibit in Second Life cannot simply exist. There needs to be a social component, someone present, to interact with visitors (or possibly to even attract visitors) (Little, 2011). The barriers for using Second Life add up as both bandwidth requirements for 3D rendering and the time necessary to simply learn how to move in the environment are high and distract from visiting exhibits or interacting with others. Libraries never seemed to take Second Life all that seriously - it was more a place for experimentation and never seemed to be adopted as a venue by patrons (Gantt and Woodland, 2013). With a commercial company now running the space and an end to the educational discount in 2010 or 2011, Second Life has become less of a space to be in, particularly for academic institutions. Even so, 3D environments for virtual library exhibits are still a tantalizing concept - in the future (Little, 2011).

\section{Conclusion}

Use of Omeka (.org and .net) at Indiana University has shown how a software tool can work at an institution to allow for discovery and access by end users to digitized collections. The choice of Omeka.org over other tools reflects the needs of our library. Omeka.org can be used in conjunction with a digital object repository like Fedora, it is easy to learn and use, provides batch import and contextual narrative capacities, is available open source, and does not require payment. While many examples from IU have been successful, such as the War of 1812 exhibit and the Student Life at IU exhibit, not everything we have tried has worked (some classroom uses showed gaps in digital collection management comprehension among students and some formats such as books did not work well with the Omeka's use of Dublin Core metadata).

For those instances where Omeka has proven useful, the most challenging problem might be managing these Omeka instances over time as each new collection is created. Within the library at Indiana University, at least four different versions of Omeka have been installed for use, which requires four different webserver paths (i.e., four completely different web sites) and four different groups of user administration access. Moving forward this method is unsustainable. Do we refuse to upgrade and remain at a certain version of Omeka so that everyone is using the same version and can be managed under a single installation? This is not feasible since new plug-ins and capabilities are developed over time and are version-

25 http://secondlife.com 
dependent. For Omeka instances that start outside of the library and are hosted on personal IU webserver accounts - how are those maintained over time? Do they eventually become the charge of the library to manage the content as part of IU's collections? Can IU make use of Omeka for its own online exhibit hosting service?

No official announcements appear on Omeka's site yet, but informal reporting from the Digital Library Federation 2013 Forum and the existence of the Omeka3 GitHub code repository show there is an Omeka3 version in the works with a plan to address just this sort of problem - one Omeka instance that can handle multiple Omeka sites. ${ }^{26,27}$ If this development takes place, a major question arises. Will older Omeka sites migrate to this new version? If not, the separate exhibit sites will remain a difficult challenge for places such as Indiana University using Omeka.

Within the range of open source, free, and pay software tools available to galleries, libraries, archives, and museums, Omeka.org presents an easier entry point for learning and growing an online exhibit presence with the flexibility to become more complex in its capabilities depending on the institution's needs. Many museums make use of a variety of tools that are not discussed in the GLAM literature (see Table 1) but do appear to serve the needs of certain institutions. A more in-depth look at the history of these tools and the needs of the GLAM community for digital object management and online exhibition would be insightful for everyone working to develop these tools and capabilities. Omeka.org is a free and open source tool designed specifically for galleries, libraries, archives, and museums to provide online access to digitized collections. Both digital object management and exhibit capabilities are included and community and developer support is constant and increasing. For those with more technological knowledge, Omeka might be somewhat restrictive as a packaged software tool but it can also be seen as a very solid base from which to offer enhanced online access to digital collections.

\section{Acknowledgements}

I would like to thank the following colleagues at Indiana University for their time and willingness to share their experiences about using Omeka: Will Cowan, Michelle Dalmau, Erika Dowell, Vivian Halloran, Christoph Irmscher, and Erika Jenns.

\footnotetext{
${ }^{26}$ https://github.com/omeka/Omeka3

27 The community reporting Google Doc linked from this session contains announcements from Omeka developer, Patrick Murray-John, of the Center for History \& New Media. http://www.diglib.org/forums/2013forum/schedule/39-2/
} 


\section{Works Cited}

Andrew, R., 2010. How to Use CSS3 Media Queries to Create a Mobile Version of Your Website. Smashing Magazine.

Bogan, K., 2011. Creating a digital archives with WordPress. In Chapter 4: Guest Pieces. Library Technology Reports 47, 47-54.

Di Pasquale, J., Palmentiero, J., Streett, L., 2013. Using Archives and Metadata to Uncover Women's Lives: Challenges and Opportunities for Scholarship through Archives and Digital Libraries. Women's History in the Digital World.

Ekart, D.F., 2012. Tech tips for every librarian. Computers in Libraries 32, 36-37.

Forbes, M., 2012. CollectionSpace: A story of open-source software development and user-centered design. Bulletin of the American Society for Information Science and Technology 38, 22-26.

Gantt, J.T., Woodland, J.R., 2013. Libraries in Second Life: Linking Collections, Clients, and Communities in a Virtual World. Journal of Web Librarianship 7, 123141.

Higgins, S., 2012. Cataloging Images Using CONTENTdm. PNLA Quarterly 76, 6-18.

Jett, J., Senseney, M., Palmer, C., 2013. A Model for Providing Web 2.0 Services to Cultural Heritage Institutions: The IMLS DCC Flickr Feasibility Study. D-Lib Magazine 19.

Lathrop, S., McDaniel, S.L., Richey, N., 2010. Exposing Ourselves: A Case Study in Collection Management Software Implementation. Southeastern Librarian $58,3-8$.

Little, G., 2011. Should I Stay or Should I Go? Academic Libraries and Second Life. The Journal of Academic Librarianship 37, 171-173.

Moses, D., Stapelfeldt, K., 2013. Renewing UPEI's Institutional Repository: New Features for an Islandora-based Environment. The Code4Lib Journal.

OCLC launches redesigned CONTENTdm, 2011. Advanced Technology Libraries 40, 5-5.

Samis, P.S., Johnson, L.F., Smith, R.S., 2007. Pachyderm: From multimedia to visual stories. J. Comput. High. Educ. 19, 3-25.

Schaefer, S., 2010. Challenges in Sustainable Open Source: A Case Study. The Code4Lib Journal.

Schwartz, S.W., Prom, C.J., Rishel, C.A., Fox, K.J., 2007. Archon: A Unified Information Storage and Retrieval System for Lone Archivists, Special Collections Librarians and Curators. Partnership: the Canadian Journal of Library and Information Practice and Research 2.

Spiro, L., 2009. Archival Management Software. Library (Enero). Disponible en: http://clir. org/pubs/reports/spiro2009. html.

Stephens, M., 2006. Chapter 6: Flickr. Library Technology Reports 42, 58-62.

Weist, J., 2010. Implementing CollectiveAccess at the Bruce High Quality Foundation University Archive. Visual Resources Association Bulletin 37, 23-26. 